\title{
Adaptive genetic differentiation in life-history traits between populations of Mimulus guttatus with annual and perennial life-cycles
}

\author{
Mark van Kleunen
}

\begin{abstract}
The optimal allocation to sexual and vegetative reproduction as well as the optimal values of other life-history characteristics such as phenology, growth and mating system are likely to depend on the life-cycle of the organism. I tested whether plants of Mimulus guttatus originating from temporarily wet populations where the species has an enforced annual life-cycle have higher allocation to sexual reproduction, lower allocation to vegetative reproduction, more rapid phenology, faster growth, and floral traits associated with a self-fertilizing mating system than plants from permanently wet populations where the species has a perennial life-cycle. I grew a total of 1377 plants originating from three populations with an annual lifecycle and 11 populations with a perennial life-cycle in a greenhouse under permanently and temporarily wet conditions. Plants of $M$. guttatus in permanently wet conditions had significantly more vegetative reproduction and tended to have a faster growth than plants in the temporarily wet conditions, indicating plasticity in these life-history traits. Plants from populations with an annual life-cycle invested significantly more in sexual reproduction and significantly less in vegetative reproduction than the ones from populations with a perennial life-cycle. Moreover, this study showed that plants originating from populations with an annual life-cycle have a significantly faster development and floral traits associated with autonomous selffertilization. In conclusion, this study suggests that there has been adaptive evolution of life history traits of $M$. guttatus in response to natural watering conditions that determine the life span of the species.
\end{abstract}

M. van Kleunen

Institute for Biochemistry and Biology, University of Potsdam, Lennéstrasse 7A,

14471 Potsdam, Germany

Present Address:

M. van Kleunen ( $₫)$

School of Biological and Conservation Sciences, University of KwaZulu-Natal,

P. Bag X01, Scottsville, Pietermaritzburg 3209, South Africa

e-mail: vankleunen@ukzn.ac.za 
Keywords Adaptive evolution - Asexual reproduction · Clonal plants · Growth $\cdot$ Mating system $\cdot$ Phenology $\cdot$ Sexual reproduction

\section{Introduction}

Most plant species (up to $80 \%$ ) have the capacity for vegetative reproduction in addition to sexual reproduction (Salisbury 1942; Klimeš et al. 1997). The balance between both modes of reproduction is one of the most important life-history characteristics of plants due to its effects on demography (Abrahamson 1980; Eriksson 1986), population genetic structure (McLellan et al. 1997; Chung and Epperson 1999; Ceplitis 2001), dispersal (Stöcklin 1999; Winkler and Fischer 2001) and meta-population processes (Piquot et al. 1998; Gabriel and Bürger 2000; Stöcklin and Winkler 2004). However, the evolution of the balance between both modes of reproduction in plants is still poorly understood (Eckert 2002; Fischer and van Kleunen 2002).

Because of a limited availability of resources or meristems, there may be a trade-off between sexual and vegetative reproduction (Harper 1977; Watson 1984; van Kleunen et al. 2002; Thompson and Eckert 2004). When such a trade-off has a genetic background, environments that select for increased allocation to sexual reproduction will indirectly select for reduced allocation to vegetative reproduction and vice versa. While sexual reproduction through seeds may allow escape from poor environmental conditions and survival of temporarily unfavourable conditions, vegetative reproduction may be beneficial as a means to remain and proliferate in benign environments (Williams 1975; Abrahamson 1980; Sackville Hamilton et al. 1987; Till-Botraud et al. 1990; Gardner and Mangel 1999). For several species, it has been shown that the allocation to sexual and vegetative reproduction may respond plastically to environmental conditions (Ogden 1974; Williams et al. 1977; Hawthorn and Cavers 1982; Schmid and Harper 1985; Humphrey and Pyke 1998; van Kleunen et al. 2001). Further, it has been shown that there may be genetic variation in the allocation to sexual and vegetative reproduction, and that these traits may respond to experimental selection (van Kleunen et al. 2002; Fischer et al. 2004). However, studies on natural genetic differentiation in allocation to both modes of reproduction are still scarce (Piquot et al. 1998; Prati and Schmid 2000; Pluess and Stöcklin 2005).

The herbaceous plant Mimulus guttatus is a highly polymorphic species which usually grows in moist habitats such as streams, wet grasslands, and on wet bluffs along the sea, and has the capacity for vegetative reproduction by layering of stems (i.e., stolons; Grant 1924; Vickery 1959). Some of these habitats remain permanently wet and there $M$. guttatus has a perennial life-cycle where stolon production is an effective way of reproduction in addition to the production of seeds. However, some of the other habitats of $M$. guttatus are drier or dry out at the end of the growing season resulting in death of all M. guttatus plants (e.g., Dole 1992). In these drier habitats, $M$. guttatus is thus enforced to an annual life-cycle, and as a consequence only sexual reproduction through seeds contributes to population persistence. $\mathrm{Mi}$ mulus guttatus is also thought to be the progenitor of several annual species within the $M$. guttatus complex such as $M$. nasutus and $M$. platycalyx which usually grow in drier habitats (Kiang and Hamrick 1978; Dole 1992). 
Here, I tested in a greenhouse experiment whether plants of $M$. guttatus from populations with an annual life-cycle have a life-history with mainly sexual reproduction and whether plants from populations with a perennial life-cycle have a lifehistory with more vegetative reproduction. Because annual plants have to reproduce within a single growing season, they may further benefit from a rapid phenology, a high growth rate (Arendt 1997), and a high capacity for reproductive assurance through autonomous selfing (Kiang and Hamrick 1978; Barrett et al. 1996). Therefore, I also tested for differences in time to anthesis, plant height, number of upright side branches, corolla width and anther-stigma separation between plants from populations with different life-cycles. Moreover, to test whether life-history traits of $M$. guttatus respond plastically to soil moisture conditions as found in their natural habitats, I grew the plants at permanently and temporarily wet conditions.

\section{Materials and methods}

\section{Study species}

The yellow monkey flower Mimulus guttatus Fisch. ex DC. (Phrymaceae, previously Scrophulariaceae; Beardsley and Olmstead 2002) is an annual or perennial herb that is native to western North America and has become naturalized in eastern North America, New Zealand and Europe. The species usually occurs in temporarily or permanently moist habitats such as small streams, ditches, wet grasslands, and on wet bluffs along the sea.

Shoots of $M$. guttatus consist of $0.1-1 \mathrm{~m}$ long upright stems which bear two opposite 1-5 cm long egg- or heart-shaped leaves at each node. Side branches and single flowers are produced from meristems in the axils of the leaves. Some side branches, especially the upper ones, grow upright and produce flowers (referred to as upright side branches hereafter), whereas most lower side branches layer and root (referred to as stolons hereafter). Although stolons may produce flowers, they mainly contribute to vegetative reproduction. As a consequence of vegetative reproduction, clones may become large and have a long life span.

In the northern hemisphere, plants may start flowering in May and continue flowering until late September if the soil does not dry out earlier as is the case for populations with an annual life-cycle. The funnel-shaped, zygomorphic, yellow flowers are 1-4 cm in length, and have conspicuous red dots at the mouth and inside the funnel. Each flower has two pairs of stamen that differ in length and which are usually exceeded by the single pistil. The species has a mixed mating system (i.e., is partly self-fertilizing; Fenster and Ritland 1994; Leclerc-Potvin and Ritland 1994; van Kleunen and Ritland 2004), and selfing rates are often negatively correlated with flower size and anther-stigma separation (Ritland and Ritland 1989; Fenster and Ritland 1994; van Kleunen and Ritland 2004). Each fruit may produce up to 500 small seeds of ca. $20 \mu \mathrm{g}$ which can germinate directly after they fall off the plant.

Plant material and experimental set-up

The plant material used in this study originated from 14 populations of $M$. guttatus in its native range from California in the south to British Columbia in the north (Table 1), and was part of a larger experiment comparing populations from the native 
Table 1 Numerical code, location and habitat description of the populations of Mimulus guttatus with annual and perennial life-cycles used in this study

\begin{tabular}{lllll}
\hline $\begin{array}{l}\text { Numerical code and } \\
\text { name of location }\end{array}$ & State or province & Latitude $\left({ }^{\circ} \mathrm{N}\right)$ & Longitude $\left({ }^{\circ} \mathrm{W}\right)$ & Habitat \\
\hline $\begin{array}{llll}\text { Annual life-cycle } \\
\text { 1. Lower Lake }\end{array}$ & California & 38.87 & 122.43 & \\
$\begin{array}{l}\text { 2. Paskenta } \\
\text { 3. Anacortes }\end{array}$ & California & 39.89 & 122.64 & $\begin{array}{l}\text { Serpentine grassland } \\
\text { Washington }\end{array}$ \\
$\begin{array}{llll}\text { Perennial life-cycle } \\
\text { 4. Walnut Creek }\end{array}$ & California & 37.51 & 122.61 & \\
5. Stone Lagoon & California & 41.18 & 121.92 & Stream edge \\
6. Orick & California & 41.35 & 124.13 & Ditch \\
7. Smith River & California & 41.93 & 124.04 & Ditch \\
8. Loss Creek & British Columbia & 48.35 & 124.01 & Ditch \\
9. Sandcut Creek & British Columbia & 48.38 & 123.99 & Ditch \\
10. Point Roberts & Washington & 48.99 & 123.06 & Ditch \\
11. Vancouver & British Columbia & 49.24 & 123.22 & Wet bluff \\
12. Port Alberni & British Columbia & 49.25 & 124.01 & Wet bluff \\
13. Courtenay & British Columbia & 49.69 & 124.99 & Ditch \\
14. Campbell River & British Columbia & 49.95 & 125.27 & Ditch \\
\hline
\end{tabular}

Latitude and longitude are given in decimal notation

range with populations from the introduced ranges in New Zealand and Europe (M. van Kleunen, unpublished data). The populations in this experiment spanned a latitudinal range of ca. $1300 \mathrm{~km}$, and the two closest populations were separated by at least $5 \mathrm{~km}$. Seeds had been collected in 2002 and 2003 by colleagues, local botanists (see acknowledgements) and the author according to the same sampling procedure. When possible, for each population one full seed capsule was collected from at least each of 19 plants (further referred to as seed families) that were at least $1 \mathrm{~m}$ apart. Although populations consisting of annual plants and populations consisting of perennial plants are both frequent in the native range, 11 of the populations consisted of perennial plants (populations with a perennial life-cycle), and only three of annual plants (populations with an annual life-cycle; Table 1).

I filled the 35 cells (diameter $=6.0 \mathrm{~cm}$, depth $=6.5 \mathrm{~cm}$ ) of each of 72 multi-pot trays with a 3:1 mixture of commercial potting compost and sand. I put each tray onto a separate drip tray, and arranged them in three equally sized groups (blocks) under natural light conditions in a greenhouse without climate control in Potsdam, Germany (latitude $52^{\circ} 24.477^{\prime} \mathrm{N}$, longitude $13^{\circ} 01.290^{\prime} \mathrm{E}$ ). Pollinating insects could easily enter the greenhouse through open windows and were abundant. Within each of the three blocks, I assigned half of the trays to a temporarily wet treatment and the other half to a permanently wet treatment that simulated watering conditions in populations with annual and perennial life-cycles, respectively. For, each of the six treatment-by-block combinations, I sowed from June 2-4, 2004 ca. ten seeds of each of the 19 seed families from each population in one randomly chosen cell with the restriction that each population was not represented more than twice in a tray. This resulted in three replicates per seed family in each treatment. For two populations with a perennial life-cycle (populations 13 and 14 in Table 1), I only had seeds of five seed families, and as a consequence the total experiment included plants of 238 instead of 266 seed families. 
During the first 3 weeks, all trays were watered from the bottom by pouring water into the drip trays to prevent seeds from floating into neighbouring cells. Thereafter, when seeds in the majority of cells $(65 \%)$ had germinated, drip trays were removed from the plants in the temporarily wet treatment to allow drainage of water. From then on plants were top watered at least every second day. This way, plants in the permanently wet treatment experienced continuously wet to water-logged conditions as is the case in most natural populations of perennial plants. Plants in the temporarily wet treatment experienced both wet and dry conditions as is also the case in most natural populations of annual plants. Each week during the first month, I thinned seedlings to one per cell thereby keeping the oldest seedling. I assigned trays to new random positions within each block every second week until plants were too large to be moved without being damaged.

\section{Measurements}

To determine the time to anthesis, I recorded at least every second day after sowing the presence of seedlings and open flowers in each cell. I calculated the time to anthesis as the number of days from germination to flowering.

At the peak of the flowering period, from August 2-6, 2004, I measured on each plant as measures of growth plant height (i.e., stem length), and counted the number of upright side branches. As measures of vegetative reproduction, I counted the number of stolons (i.e., layering branches) and measured the length of the longest stolon. I differentiated between upright side branches and stolons by whether the branches grew upward from the main stem or were layering, respectively. As an estimate of sexual reproduction, I counted the number of flowers (including flower buds and seed capsules). Further, I collected one randomly chosen seed capsule from each plant in one of the three experimental blocks (i.e., for one of the three replicates per seed family and treatment combination), and counted the number of seeds. As estimates of floral size and herkogamy, I measured the width of the corolla and the distance between the stigma tip and the upper pair of anthers (i.e., anther-stigma separation) on the most recently fully opened flower on each plant.

\section{Analyses}

Because the number of populations in each life-cycle category was unbalanced, I analysed the data with restricted maximum likelihood analysis of variance (REML) using the statistical software GenStat (Lawes Agricultural Trust, Rothamsted, UK). REML provides efficient estimates of treatment effects in unbalanced designs with more than one source of error (Payne et al. 2005). I considered 'watering treatment' (permanently wet and temporarily wet), and 'life-cycle' (annual and perennial) as fixed factors, and tested their significance and the one of their interaction with the Wald test statistic (type III), which has an asymptotic chi-squared distribution (Dobson 1990). I considered 'block', 'tray', 'population' and 'seed family' as random factors, and tested their significance and the ones of their interactions using the change in deviance after removing these terms from the model. The change in deviance is approximately chi-squared distributed (Littell et al. 1996). 'Tray' was nested within 'block' and 'watering treatment', 'population' was nested within 'life-cycle', and 'seed family' was nested within 'population'. Although I did not aim at studying latitudinal clinal variation in this study, I accounted for potentially 
confounding effects of latitude of origin with 'life-cycle' by including 'latitude' as a covariate in the random model. When the analyses revealed a significant association between a trait and latitude, the sign of the association was assessed by calculating the Pearson's correlation coefficient between the mean trait value of a population and its latitude. For the analysis of the number of seeds per capsule, I did not include the 'block' factor and the 'watering treatment-by-seed family' interaction because this trait was only measured in one of the three experimental blocks. To achieve normality and homoscedasticity, time to anthesis and number of seeds per capsule were $\log 10$-transformed, and number of upright side branches, number of stolons, length of the longest stolon and number of flowers were square-root transformed prior to analyses.

\section{Results}

Plant phenology

On average, plants from populations with a perennial life-cycle started to flower significantly later by 9 days than the ones from populations with an annual lifecycle (Fig. 1a; Table 2). There was a significant effect of the latitude of population origins (Table 2). The Pearson's correlation coefficient between latitude and the mean population value of time to anthesis, however, was close to zero (Pearson's $r=0.017, P=0.953, N=14$ ) but the correlation was negative when the annual and perennial populations were analysed separately (annual populations: Pearson's $r=-0.702, \quad P=0.504, \quad N=3$; perennial populations: Pearson's $r=-0.396$, $P=0.228, N=11$ ). This indicates that after taking account of population life-cycle, plants from high latitude started flowering earlier than the ones from low latitude. The remaining variation in time to anthesis among populations was not significant but the variation among seed families within populations was significant (Table 2). Time to anthesis was slightly delayed $(-2.3 \%)$ by the permanently wet treatment compared to the temporarily wet treatment (Fig. 1a) but this effect was not significant $\left(\chi_{1}=3.59, P=0.058\right.$; Table 2$)$. Seed families within populations differed significantly in plasticity of time to anthesis in response to the watering treatment (Table 2).

Plant growth

On average, plants from populations with a perennial life-cycle grew significantly less tall $(-19.4 \%)$ and produced fewer upright side branches $(-74.3 \%)$ than plants from populations with an annual life-cycle (Fig. 1b, c; Table 2). There was a significant effect of latitude of origin on the number of upright side branches (Table 2). The negative Pearson's correlation coefficient between latitude and the mean population value of number of upright branches (Table 2; Pearson's $r=-0.593, P=0.026, N=14$ ) indicates that plants from high latitude produced fewer upright side branches than the ones from low latitude. The remaining variation in number of upright side branches and the variation in plant height among population were not significant, but there was significant variation among seed families within populations for both traits (Table 2). On average, plants in the permanently wet treatment grew taller $(+12.7 \%)$ than plants in the temporarily wet 

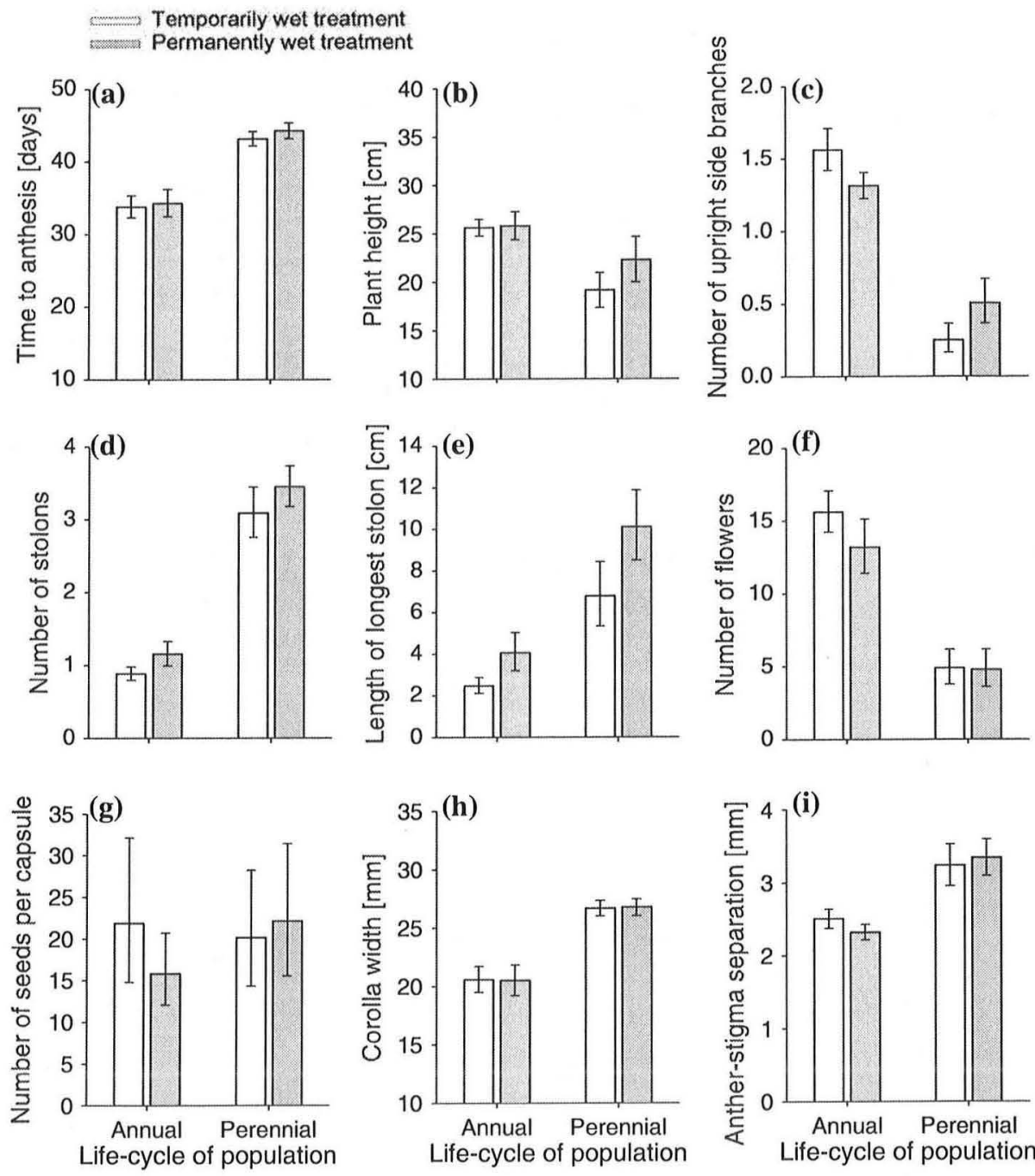

Fig. 1 Means $( \pm 1$ SE for untransformed data, and +1 upper SE and -1 lower SE for transformed data after back transformation) of (a) time to anthesis, (b) plant height, (c) number of upright side branches, (d) number of stolons, (e) length of the longest stolon, (f) number of flowers, (g) number of seeds per capsule (h) corolla width, and (i) anther-stigma separation of populations of Mimulus guttatus with annual and perennial life-cycles grown under temporarily wet (open bars) and permanently wet (shaded bars) soil conditions

treatment, although this effect was not significant $\left(\chi_{1}=3.37, P=0.067\right.$; Table 2) and most pronounced for plants from populations with a perennial life-cycle (Fig. 1b; significant watering treatment-by-life-cycle interaction in Table 2). The number of upright side branches was reduced by the permanently wet treatment in plants from populations with an annual life-cycle while it increased in the ones from populations with perennial life-cycles (Fig. 1c; significant watering treatmentby-life-cycle interaction in Table 2). 
Table 2 Summary of restricted maximum likelihood analyses of variance of effects of watering treatment and population life-cycle on phenology, growth, reproduction and floral traits of Mimulus guttatus

\begin{tabular}{|c|c|c|c|c|c|c|c|c|c|}
\hline & $\begin{array}{l}\text { Time to } \\
\text { anthesis }\end{array}$ & $\begin{array}{l}\text { Plant } \\
\text { height }\end{array}$ & $\begin{array}{l}\text { No. of side } \\
\text { branches }\end{array}$ & $\begin{array}{l}\text { No. of } \\
\text { stolons }\end{array}$ & $\begin{array}{l}\text { Length of } \\
\text { longest stolon }\end{array}$ & $\begin{array}{l}\text { No. of } \\
\text { flowers }\end{array}$ & $\begin{array}{l}\text { No. of seeds } \\
\text { per capsule }\end{array}$ & $\begin{array}{l}\text { Corolla } \\
\text { width }\end{array}$ & $\begin{array}{l}\text { Anther-stigma } \\
\text { separation }\end{array}$ \\
\hline \multicolumn{10}{|l|}{ Fixed model } \\
\hline Watering treatment & 3.59 & 3.37 & 1.87 & $4.91 *$ & $6.67 *$ & 0.32 & 0.47 & 0.95 & 0.63 \\
\hline Life-cycle & $179.41 * * *$ & $6.13^{*}$ & $22.92 * * *$ & $203.20 * * *$ & $40.70 * * *$ & $12.86 * * *$ & 0.53 & $241.54 * * *$ & $24.65^{* * *}$ \\
\hline$W \times L$ & 0.58 & $6.14^{*}$ & $12.59 * * *$ & 0.35 & 1.78 & $4.85^{*}$ & 0.54 & 0.00 & 2.36 \\
\hline \multicolumn{10}{|l|}{ Random model } \\
\hline Block & 2.49 & $4.32 *$ & 0.54 & 0.00 & $15.53 * * *$ & 3.44 & - & 3.16 & 0.00 \\
\hline $\operatorname{Tray}(\mathrm{B}, \mathrm{W})$ & 1.63 & $15.42 * * * *$ & $112.06^{* * * *}$ & $39.98^{* * * *}$ & $5.38^{*}$ & 2.19 & 0.00 & 0.03 & 1.91 \\
\hline Latitude & $56.50^{* * *}$ & 1.73 & $51.53^{* * * *}$ & 0.10 & $13.18^{* * *}$ & 1.45 & 0.00 & 0.00 & $10.77^{* * * *}$ \\
\hline Population(L) & 1.46 & 0.00 & 3.51 & 3.77 & $6.97 * *$ & $4.64 *$ & 1.22 & 0.01 & $6.98^{* *}$ \\
\hline Seed family $(\mathrm{L}, \mathrm{P})$ & $48.04 * * *$ & $46.78^{* * *}$ & $22.07 * * *$ & 3.50 & $6.07^{*}$ & $129.66 * * *$ & 0.39 & $17.09 * * *$ & $29.28 * * *$ \\
\hline $\mathrm{W} \times \mathrm{P}(\mathrm{L})$ & 0.00 & 0.13 & 0.12 & 0.00 & 0.00 & 0.00 & 0.00 & 0.00 & 0.00 \\
\hline $\mathrm{W} \times \mathrm{S}(\mathrm{L}, \mathrm{P})$ & $4.40 *$ & 0.00 & 0.22 & 2.35 & 0.00 & 0.00 & - & 0.00 & 0.00 \\
\hline
\end{tabular}

Fixed effects were tested with Wald tests, and random effects with the change in deviance after removing the effect from the full model. Both the Wald test and the change in deviance are chi-squared distributed with $1 \mathrm{df}$. Prior to analyses, time to anthesis and number of seeds per capsule were log 10 -transformed, and number of upright side branches, number of stolons, length of longest stolon, and number of flowers were square-root transformed

$* P<0.05 ; * * P<0.01 ; * * * P<0.001$ 
Allocation to sexual and vegetative reproduction

On average, plants from populations with a perennial life-cycle produced significantly more $(+322 \%)$ and longer $(+260 \%)$ stolons than plants from populations with an annual life-cycle (Fig. 1d, e; Table 2). On the other hand, the number of flowers was significantly higher $(+277 \%)$ for plants from populations with an annual lifecycle than for plants from populations with a perennial life-cycle (Fig. 1f; Table 2). The number of seeds per capsule, however, did not differ significantly between the two life-cycle categories (Fig. 1g; Table 2). There was a significantly positive effect of the latitude of origin on the length of the longest stolon (Table 2; Pearson's $r=0.462, P=0.097, N=14)$. Moreover, the remaining variation in length of the longest stolon and the variation in number of stolons among populations within lifecycle categories was significant (Fig. 2; Table 2). There was also significant variation among seed families within populations for both the number and length of stolons (Table 2). The number of stolons and the length of the longest stolon were significantly higher $(+14.0 \%$ and $+51.0 \%$, respectively) in the permanently wet treatment than in the temporarily wet treatment (Fig. 1d, e; Table 2) but there was no significant effect of watering treatment on the number of flowers and the number of seeds per capsule (Fig. 1f, g; Table 2).

Fig. 2 Means (+1 upper SE and -1 lower SE after back transformation of the transformed data) of (a) length of the longest stolon, and (b) number of flowers of populations of Mimulus guttatus with annual (open symbols) and perennial (closed symbols) life-cycles.

Population codes are given in Table 1
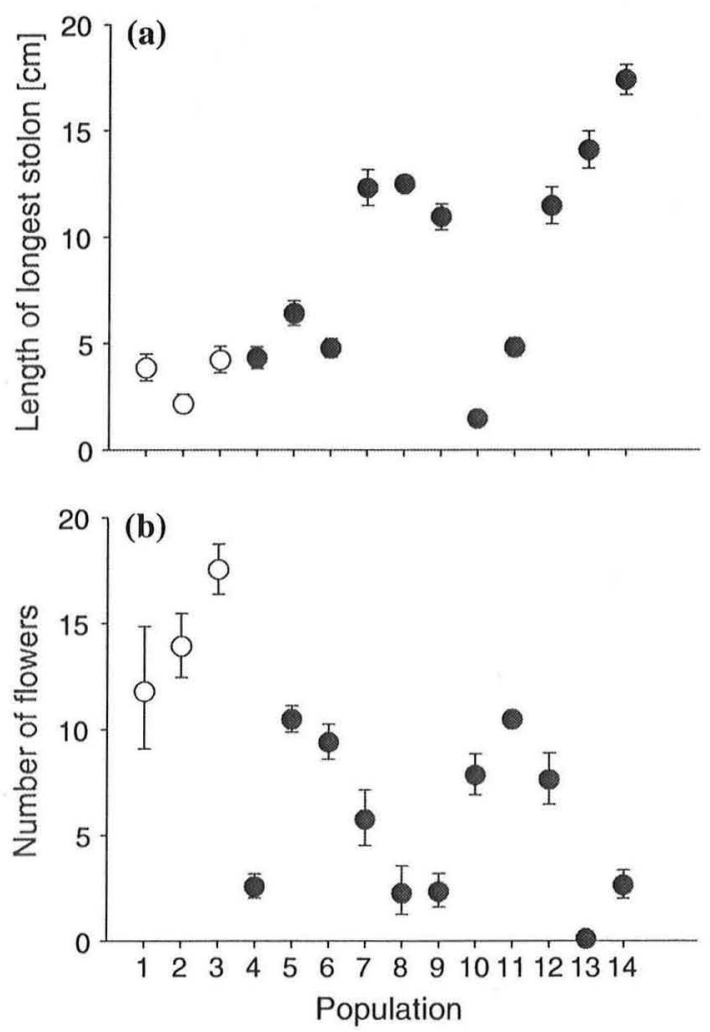


\section{Floral traits}

On average, plants from populations with a perennial life-cycle had a significantly larger corolla width $(+30.0 \%)$ and larger anther-stigma separation $(+36.3 \%)$ than plants from populations with an annual life-cycle (Fig. 1h, i; Table 2). For antherstigma separation, there was a significant effect of the latitude of origin (Table 2). The Pearson's correlation coefficient between latitude and the mean population value of anther-stigma separation, however, did not reveal the sign of this association (Pearson's $r=0.082, P=0.781, N=14$ ). The remaining variation in antherstigma separation among populations within life-cycle categories was also significant (Table 2). For both floral traits, there was significant variation among seed families within populations (Table 2). None of the floral traits was significantly affected by the watering treatment (Fig. 1h, i; Table 2).

\section{Discussion}

Plants of $M$. guttatus in permanently wet conditions produced more and longer stolons, tended to be taller and tended to start flowering later than plants in temporarily wet conditions. This shows that soil moisture conditions affect important life-history traits of $M$. guttatus. In line with the direction of these plastic responses, plants from permanently wet populations with a perennial life-cycle started to flower later, and produced more and longer stolons than plants from temporarily wet populations with an annual life-cycle. For plant height, however, the positive effect of permanency of the wet soil conditions was only present for populations with a perennial life-cycle, and this effect was opposite to the genetic differentiation for plant height between populations with annual and perennial life-cycles. Although further studies using either selection gradient analysis (e.g., Dudley 1996; van Kleunen and Fischer 2001, 2005) or phenotypic manipulation (e.g., Dudley and Schmitt 1996) are required to test for adaptive plasticity in phenology and vegetative reproduction, the similarity in direction of genetic and environmental influences on these traits suggests that their plastic responses may be adaptive.

In addition to the differences in time to anthesis and vegetative reproduction, plants from populations with a perennial life-cycle also produced fewer upright side branches and flowers, and larger flowers with a larger anther-stigma separation than the ones from populations with an annual life-cycle. Moreover, plants from populations with an annual life-cycle and the ones from populations with a perennial lifecycle differed in their plasticity of plant height and the number of upright side branches in response to the watering treatment. This indicates that there is considerable quantitative genetic differentiation among plants of $M$. guttatus from populations with annual and perennial life-cycles in important life-history traits and their plasticities. An alternative explanation could be that differences among the life-cycle categories are a consequence of maternal environmental carry-over effects through seeds (Schmid and Dolt 1994; Weiner et al. 1997). Galloway (1995) suggested that maternal environmental carry-over effects may affect phenology and sexual and vegetative reproduction of $M$. guttatus through effects on seedling size. Although I do not have data on seedling size, unpublished data on a subsample of the seed families used in this experiment, showed that the average volume of single seeds did not differ between populations with annual (mean $\pm \mathrm{SE}$ 
$\left.=4.42 \pm 0.77 \mathrm{~mm}^{3}\right)$ and perennial $\left(4.16 \pm 0.15 \mathrm{~mm}^{3} ; \chi_{1}=1.33, P=0.249\right)$ life-cycles. This indicates that there were no differences in maternal seed provisioning between annual and perennial populations. Moreover, maternal carry-over effects are often transient and are therefore most likely to affect early life-history traits such as the time to germination and the size of seedlings rather than later life-history traits such as the balance between sexual and vegetative reproduction. Therefore, the observed differences between populations with annual and perennial life-cycles are most likely to represent quantitative genetic differentiation rather than maternal environmental carry-over effects.

Genetic variation in the allocation to sexual and vegetative reproduction is a prerequisite for evolution of these traits but has been tested for only a few clonal plant species (Schmid and Weiner 1993; Prati and Schmid 2000; van Kleunen et al. 2002). So far, it has been shown for only one other species, Ranunculus reptans, that intraspecific genetic differentiation in the allocation to both modes of reproduction is related to the habitat of origin (Prati and Schmid 2000). In another recent study, Pluess and Stöcklin (2005) did not find significant genetic differentiation in sexual and vegetative reproduction for plants of Geum reptans from low and high altitudes, and from early and late successional habitats. Further, Piquot et al. (1998) found that plants of the aquatic clonal macrophyte Sparganium erectum from newly established populations invested more in sexual reproduction than plants from older populations, indicating that meta-population dynamics may also play an important role in the evolution of reproductive allocation of clonal plants.

I found genetic variation for both sexual and vegetative reproduction within and among populations of $M$. guttatus. Overall, however, plants of $M$. guttatus from populations with a perennial life-cycle had more vegetative reproduction while plants from populations with an annual life-cycle had more sexual reproduction. The observed differences in reproductive allocation at the moment of measurement could be a consequence of delayed development of plants from populations with a perennial life-cycle. However, by the end of the growing season, when all plants had stopped producing new flowers, the difference in the number of flowers was still present (annual: mean \pm upper SE/lower SE $=16.37 \pm 1.66 / 1.58$, perennial: $\left.5.70 \pm 1.62 / 1.42 ; \chi_{1}=8.45, P=0.004\right)$. The observed genetic differentiation in reproductive allocation is in line with the hypothesis that a high allocation to sexual reproduction is an adaptation in temporarily wet populations with an annual lifecycle and that a high allocation to vegetative reproduction is an adaptation in permanently wet populations with a perennial life-cycle. Dole (1992) also found in a comparison of 10 populations belonging to $M$. guttatus and the closely related species $M$. nasutus and M. platycalyx that the ones from populations with a perennial lifecycle had a higher vegetative reproduction than the ones from populations with annual life-cycles. However, when he only compared the five populations belonging to $M$. guttatus, this effect was still present but not significant anymore. Till-Botraud et al. (1990) found that plants of Pоа аппиа from a permanently irrigated golf field where the species had a perennial life-cycle invested less in sexual reproduction but more in vegetative growth than plants from an adjacent non-irrigated site where the species had an annual life-cycle. Together with these studies, this study shows that watering conditions that determine the life span of a species may result in adaptive evolution of reproductive allocation.

For plants with a relatively short growing period, rapid phenology and a high growth rate may allow sufficient seed production before unfavourable conditions 
start (Arendt 1997). In line with this hypothesis, I found that plants from higher latitude populations, which naturally have shorter growing seasons, had a shorter time to anthesis than plants from lower latitude populations. Such a latitudinal cline in time to anthesis is also often found for other species (e.g., Weber and Schmid 1998; Olsson and Agren 2002). Moreover, plants from populations with an annual life-cycle that usually have a short growing season took on average about 9 days less to start flowering than plants from populations with a perennial life-cycle (Fig. 1a). Moreover, plants from populations with an annual life-cycle grew higher and produced more branches than the ones from populations with a perennial life-cycle. This suggests that the observed genetic differentiation in phenology and growth between populations with annual and perennial life-cycles might be adaptive.

Plants of $M$. guttatus from populations with an annual life-cycle had smaller flowers and anther-stigma separation than plants from populations with a perennial life-cycle. Previous studies have shown that small flowers of $M$. guttatus receive less pollinator visits than large flowers (Martin 2004; Ivey and Carr 2005). This indicates that plants of $M$. guttatus with small flowers may depend more on reproductive assurance through autonomous self-pollination than the ones with large flowers. Although a recent study suggests that self-fertilization in $M$. guttatus is mainly affected by the morphology of the lower corolla lip (Arathi and Kelly 2004), other studies have shown that small flowers and small anther-stigma separation are often, although not always (e.g., Ivey and Carr 2005), associated with high selfing rates in M. guttatus (Ritland and Ritland 1989; Carr and Fenster 1994; Fenster and Ritland 1994; Robertson et al. 1994; van Kleunen and Ritland 2004). Therefore, my results suggest that plants from populations with an annual life-cycle may have a higher potential for autonomous seed set than populations with a perennial life-cycle. Indeed, Dole (1992) found in a comparison of 10 populations belonging to $M$. guttatus and the closely related species $M$. nasutus and $M$. platycalyx that the ones from populations with an annual life-cycle had a higher autonomous seed set than the ones from populations with a perennial life-cycle. However, when he only compared the five populations belonging to $M$. guttatus, this effect was still present but not significant anymore. Although it is likely that floral traits affect selfing rates, also the reverse, i.e., that floral traits depend on the level of inbreeding might be true (Kelly and Arathi 2003; Ivey and Carr 2005). Nevertheless, because reproductive assurance through autonomous selfing is likely to be more important for plants with a single flowering season than for plants that have multiple flowering seasons (Barrett et al. 1996), the observed genetic differentiation in floral traits between populations with annual and perennial life-cycles is most likely adaptive.

While most of the measured life-history traits of $M$. guttatus showed genetic differentiation between populations with annual and perennial life-cycles, some traits still showed significant variation among populations within life-cycle categories. This indicates that other evolutionary processes such as genetic drift may affect the evolution of life-history traits in populations of $M$. guttatus or that factors other than permanency of wet soil conditions impose selection on life-history traits. Evidence for the latter is provided by significant latitudinal clines for some of the traits (Table 2). Moreover, most traits showed significant variation among seed families within populations which indicates that there is still potential for further evolution of these life-history traits in most populations of $M$. guttatus. On the other hand, seed families only showed significant variation in plastic responses to the watering treatments for time to anthesis. Although the low amount of genetic variation in 
plasticity might be an artifact of the unbalanced experimental design, it most likely indicates that for most traits plastic responses to soil water conditions are fixed within the studied populations of $M$. guttatus. Similarly, Pigliucci et al. (1995) found no significant genetic variation in plasticity of phenology, growth and reproduction in response to watering treatments for Arabidopsis thaliana. Further, in a review, including 41 studies on genetic variation in plasticity, Scheiner (1993) reports that genetic variation in plasticity was lower than genetic variation in trait mean values in 25 of the studies, while the reverse was found in nine studies. In the seven remaining studies of this review, the difference in genetic variation between plasticity and trait mean values depended on the trait, population or sex. Together with my study, these results indicate that there is often a low potential for evolution of plastic responses compared to trait mean values.

\section{Conclusions}

This study shows that important life-history traits of $M$. guttatus can respond plastically to soil moisture conditions, and that these plastic responses are most likely adaptive. Moreover, important life-history characteristics including phenology, growth, reproductive allocation and floral traits associated with the mating system differed between plants from permanently wet populations with a perennial lifecycle and plants from temporarily wet populations with an annual life-cycle. This indicates that natural environmental conditions that determine the life span of the species may impose strong selection on life-history traits.

Acknowledgements I thank Allison Butlen, Elizabeth Parnis, Jessica Ruvinsky, Linda Jennings, Marilyn Barker, Lawrence Janeway, Lowel Ahart, Nick Page, Nishanta Rajakaruna and Tony Labanca for collecting seeds, Anna Wojciechowska, Dorit Raudnitschka, Ines Schneider, Lena Blischke, Vanessa Pasqualetto, and Stefan Dietrich for practical assistance, Markus Fischer, two anonymous reviewers and the associated editor for helpful comments on earlier versions of the ms and the Swiss Science Foundation for support.

\section{References}

Abrahamson WG (1980) Demography and vegetative reproduction. In: Solbrig OT (ed) Demography and evolution in plant populations. Blackwell Scientific Publications, Oxford, pp 89-106

Arathi HS, Kelly JK (2004) Corolla morphology facilitates both autogamy and bumblebee pollination in Mimulus guttatus. Int J Plant Sci 165:1039-1045

Arendt JD (1997) Adaptive intrinsic growth rates: an integration across taxa. Q Rev Biol 72:149-177

Barrett SCH, Harder LD, Worley AC (1996) The comparative biology of pollination and mating in flowering plants. Philos T Roy Soc B 351:1271-1280

Beardsley PM, Olmstead RG (2002) Redefining Phrymaceae: the placement of Mimulus, tribe Mimuleae, and Phryma. Am J Bot 89:1093-1102

Carr DE, Fenster CB (1994) Levels of genetic variation and covariation for Mimulus (Scrophulariaceae) floral traits. Heredity 72:606-618

Ceplitis A (2001) The importance of sexual and asexual reproduction in the recent evolution of Allium vineale. Evolution 55:1581-1591

Chung MG, Epperson BK (1999) Spatial genetic structure of clonal and sexual reproduction in populations of Adenophora grandiflora (Campanulaceae). Evolution 53:1068-1078

Dobson AJ (1990) An introduction to generalized linear models. Chapman and Hall, London

Dole JA (1992) Reproductive assurance mechanisms in three taxa of the Mimulus guttatus complex (Scrophulariaceae). Am J Bot 79:650-659 
Dudley SA (1996) Differing selection on plant physiological traits in response to water availability: a test of adaptive hypotheses. Evolution 50:92-102

Dudley SA, Schmitt J (1996) Testing the adaptive plasticity hypothesis: density-dependent selection on manipulated stem length in Impatiens capensis. Am Nat 147:445-465

Eckert CG (2002) The loss of sex in clonal plants. Evol Ecol 15:501-520

Eriksson O (1986) Survivorship, reproduction and dynamics of ramets of Potentilla anserina on a Baltic seashore meadow. Vegetatio 67:17-25

Fenster CB, Ritland K (1994) Evidence for natural selection on mating system in Mimulus (Scrophulariaceae). Int J Plant Sci 155:588-596

Fischer M, van Kleunen M (2002) On the evolution of clonal plant life histories. Evol Ecol 15:565-582

Fischer M, van Kleunen M, Schmid B (2004) Experimental life-history evolution: selection on growth form and its plasticity in a clonal plant. J Evol Biol 17:331-341

Gabriel W, Bürger R (2000) Fixation of clonal lineages under Muller's ratchet. Evolution 54:1116-1125

Galloway LF (1995) Response to natural environmental heterogeneity: maternal effects and selection on life-history characters and plasticities in Mimulus guttatus. Evolution 49:1095-1107

Gardner SN, Mangel M (1999) Modeling investments in seeds, clonal offspring, and translocation in a clonal plant. Ecology 80:1202-1220

Grant AL (1924) A monograph of the genus Mimulus. Ann Miss Bot Gard 11:99-193

Harper JL (1977) The population biology of plants. Academic Press, New York

Hawthorn WR, Cavers PB (1982) Dry weight and resource allocation patterns among individuals in populations of Plantago major and P. rugelii. Can J Bot 60:2424-2439

Humphrey LD, Pyke DA (1998) Demographic and growth responses of guerrilla and phalanx perennial grass in competitive mixtures. J Ecol 86:854-865

Ivey CT, Carr DE (2005) Effects of herbivory and inbreeding on the pollinators and mating system of Mimulus guttatus (Phrymaceae). Am J Bot 92:1641-1649

Kelly JK, Arathi HS (2003) Inbreeding and the genetic variance in floral traits of Mimulus guttatus. Heredity 90:77-83

Kiang YT, Hamrick JL (1978). Reproductive isolation in the Mimulus guttatus-M. nasutus complex. Am Midl Nat 100:269-276

Klimeš L, Klimešová J, Hendriks R, van Groenendael J (1997) Clonal plant architecture: a comparative analysis of form and function. In: de Kroon H, van Groenendael J (eds) The ecology and evolution of clonal plants. Backhuys Publishers, Leiden, pp 1-29

Leclerc-Potvin C, Ritland K (1994) Modes of self-fertilization in Mimulus guttatus (Scrophulariaceae): a field experiment. Am J Bot 81:199-205

Littell RC, Milliken GA, Stroup WW, Wolfinger RD (1996) SAS system for mixed models. SAS Institute, Cary

Martin NH (2004) Flower size preferences of the honeybee (Apis mellifera) foraging on Mimulus guttatus (Scrophulariaceae). Evol Ecol Res 6:777-782

McLellan AJ, Prati D, Kaltz O, Schmid B (1997) Structure and analysis of phenotypic and genetic variation in clonal plants. In: de Kroon H, van Groenendael J (eds) The ecology and evolution of clonal plants. Backhuys Publishers, Leiden, pp 185-210

Ogden J (1974) The reproductive strategy of higher plants: II. The reproductive strategy of Tussilago farfara $\mathrm{L}$. J Ecol 62:291-324

Ollson K, Ågren J (2002) Latitudinal population differentiation in phenology, life history and flower morphology in the perennial herb Lythrum salicaria. J Evol Biol 15:983-996

Payne RW, Harding SA, Murray DA, Soutar DM, Baird DB, Welham SJ, Kane AF, Gilmour AR, Thompson R, Webster R, Tunnicliffe Wilson G (2005) The guide to GenStat release 8. Part 2: statistics. VSN International, Oxford, UK

Pigliucci M, Whitton J, Schlichting CD (1995) Reaction norms of Arabidopsis. 1. Plasticity of characters and correlations across water, nutrients and light gradients. J Evol Biol 8:421-438

Piquot Y, Petit D, Valero M, Cuguen J, de Laguerie P, Vernet P (1998) Variation in sexual and asexual reproduction among young and old populations of the perennial macrophyte Sparganium erectum. Oikos 82:139-148

Pluess AR, Stöcklin J (2005) The importance of population origin and environment on clonal and sexual reproduction in the alpine plant Geum reptans. Funct Ecol 19:228-237

Prati D, Schmid B (2000) Genetic differentiation of life-history traits within populations of the clonal plant Ranunculus reptans. Oikos 90:442-456 
Ritland C, Ritland K (1989) Variation of sex allocation among eight taxa of the Mimulus guttatus species complex (Scrophulariaceae). Am J Bot 76:1731-1739

Robertson AW, Diaz A, Macnair MR (1994) The quantitative genetics of floral traits in Mimulus guttatus. Heredity 72:300-311

Sackville Hamilton NR, Schmid B, Harper JL (1987) Life-history concepts and the population biology of clonal organisms. Proc Roy Soc B Biol Sci 232:35-57

Salisbury EJ (1942) The reproductive capacity of plants: studies in quantitative biology. G. Bell and Sons, London

Scheiner SM (1993) Genetics and evolution of phenotypic plasticity. Ann Rev Ecol Syst 24:35-68

Schmid B, Dolt C (1994) Effects of maternal and paternal environment and genotype on offspring phenotype in Solidago altissima L. Evolution 48:1525-1549

Schmid B, Harper JL (1985) Clonal growth in grassland perennials. II. Growth form and fine-scale colonization ability. J Ecol 73:809-818

Schmid B, Weiner J (1993) Plastic relationships between reproductive and vegetative mass in Solidago altissima. Evolution 47:61-74

Stöcklin J (1999) Differences in life history traits of related Epilobium species: clonality, seed size and seed number. Folia Geobot 34:7-18

Stöcklin J, Winkler E (2004) Optimum reproduction and dispersal strategies of a clonal plant in a metapopulation: a simulation study with Hieracium pilosella. Evol Ecol 18:563-584

Thompson FL, Eckert CG (2004) Trade-offs between sexual and clonal reproduction in an aquatic plant: experimental manipulations vs. phenotypic correlations. J Evol Biol 17:581-592

Till-Botraud I, Wu L, Harding J (1990) Rapid evolution of life history traits in populations of Poa аппиа L. J Evol Biol 3:205-224

van Kleunen M, Fischer M (2001) Adaptive evolution of plastic foraging responses in a clonal plant. Ecology 82:3309-3319

van Kleunen M, Fischer M (2005) Constraints on the evolution of adaptive phenotypic plasticity in plants. New Phytol 166:49-60

van Kleunen M, Fischer M, Schmid B (2001) Effects of intraspecific competition on size variation and reproductive allocation in a clonal plant. Oikos 94:515-524

van Kleunen M, Fischer M, Schmid B (2002) Experimental life-history evolution: selection on the allocation to sexual reproduction and its plasticity in a clonal plant. Evolution 56:2168-2177

van Kleunen M, Ritland K (2004) Predicting evolution of floral traits associated with mating system in a natural plant population. J Evol Biol 17:1389-1399

Vickery RK (1959) Barriers to gene exchange within Mimulus guttatus (Scrophulariaceae). Evolution 13:300-310

Watson MA (1984) Developmental constraints: effect on population growth and patterns of resource allocation in a clonal plant. Am Nat 123:411-426

Weber E, Schmid B (1998) Latitudinal population differentiation in two species of Solidago (Asteraceae) introduced into Europe. Am J Bot 85:1110-1121

Weiner J, Martinez S, Müller-Schärer H, Stoll P, Schmid B (1997) How important are environmental maternal effects in plants? A study with Centaurea maculosa. J Ecol 85:133-142

Williams GC (1975) Sex and evolution. Princeton University Press, New Jersey

Williams RD, Quimby PC, Frick KF (1977) Intraspecific competition of purple nutsedge (Cyperus rotundus) under greenhouse conditions. Weed Sci 25:477-481

Winkler E, Fischer M (2001) The role of vegetative and seed dispersal within habitats for optimal life histories of clonal plants: a simulation study. Evol Ecol 15:281-301 